\title{
Reduction and Reforming of Tar with Enhanced Volatile-Char Interaction during Coal Pyrolysis
}

\author{
Y. Kawabata, T. Wajima, H. Nakagome, S. Hosokai, Y. Suzuki, and K. Matsuoka
}

\begin{abstract}
We attempted to reduce and reform tar-derived pyrolysis during coal gasification. Volatile-char contact can be used to reduce tar emissions. We developed a novel circulating fluidized bed consisting of a bubbling bed pyrolyzer and combustor made of quartz for direct observation of the solids' behavior. Raw coal was fed to the pyrolyzer $\left(700-900^{\circ} \mathrm{C}\right)$ and gases, tar, and char were formed. The resultant char was circulated with bed material to the combustor, and combusted completely or partially. During partial combustion, some chars were combusted, and the uncombusted chars were circulated back to the pyrolyzer (termed char recycling). During char recycling, the recycled char could contact tar derived from pyrolysis, and the volatile-char interaction was enhanced with char recycling time. The product gas yield, mainly $\mathrm{H}_{2}$ and $\mathrm{CO}$, increased, whereas the heavy and light tar yields decreased with char recycling.
\end{abstract}

Index Terms - Circulating fluidized bed, coal pyrolysis, tar reduction, tar reforming, volatile-char interaction.

\section{INTRODUCTION}

Gasification is an important clean coal technology, because the product gas, i.e., syngas, can be used for various purposes such as power generation, and as a raw material for liquid fuel and chemical synthesis. The efficiency of an integrated coal-gasification combined cycle (IGCC) is higher than that of conventional coal-fired power generation. In Japan, an IGCC has been operated by JOBAN Joint Power Co., Ltd. on a commercial scale, and the power generation efficiency (lower heating value basis) with a $1200^{\circ} \mathrm{C}$ class gas turbine (GT) reached $42 \%$ [1].

More recently, an advanced IGCC (A-IGCC) has been proposed [2]. The A-IGCC exhibits a higher power generation efficiency compared with conventional IGCC. The A-IGCC system is based on an exergy recuperation concept that involves the recycling of exhaust heat of the GT via an endothermic reaction during steam gasification. The A-IGCC system can improve the thermal efficiency. Its overall efficiency is theoretically higher than that of a conventional IGCC system, which uses an

Manuscript received September 5, 2014; revised November 17, 2014 The authors gratefully acknowledge the financial support provided by the Japan Science and Technology Agency under the Strategic International Collaborative Research Program. Part of this work was performed under the Cooperative Research Program of the "Network Joint Research Center for Materials and Devices".

Y. Kawabata, T. Wajima, and H. Nakagome are with the Department of Urban Environment Systems, Graduate School of Engineering, Chiba University, Chiba, Japan (e-mail: z8t0266@students.chiba-u.jp, wajima@tu.chiba-u.ac.jp, nakagome@tu.chiba-u.ac.jp).

S. Hosokai, Y. Suzuki, and K. Matsuoka are with the Clean Gas Group, Energy Technology Research Institute, National Institute of Advanced Industrial Science and Technology, Tsukuba, Japan (e-mail: koichi-matsuoka@aist.go.jp). entrained-bed-type gasifier. In the A-IGCC system, coal is gasified at a relatively low temperature $(<1173 \mathrm{~K})$ using only steam generated by the exhaust heat of the GT. Reactor design for low-temperature steam gasification of coal is essential for development of the A-IGCC system. A fluidized bed-type gasification reactor could be suitable because the residence time (i.e., reaction time) of the coal in the fluidized bed gasifier can be adjusted. However, in the low-temperature gasification process, a decrease in char gasification rate and the evolution of a large amount of tar are important issues for chemical reaction control. We have proposed isolation of the pyrolysis from the gasification zone in a circulating fluidized bed reactor to promote char gasification [3]. The char gasification rate increased as a result of the isolation. However, tar emission still remained an issue for attainment of low-temperature gasification. Many researchers have reported on methods to reduce tar, such as partial oxidation [4], [5], catalytic decomposition [6]-[10], and char utilization [11]-[22]. Char utilization has advantages such as the avoidance of catalyst deactivation by impurities in the coal, such as sulfur and chlorine, and low cost. Zhang et al. [17] examined tar reduction during rapid pyrolysis in the presence of steam in a drop tube furnace (DTF) reactor. They fed raw coal with char in different mixing ratios into the DTF reactor. Tar formed from the pyrolysis of raw coal can be cracked or reformed by the char that is co-fed in the DTF. Matsuoka et al. [19] suggested the possibility of tar reduction in a circulating fluidized bed reactor (CFB) for high-char concentrations. However, some ambiguity exists regarding tar reduction by the interaction of tar with char. In this study, we developed a CFB reactor and examined the effect of operating conditions on tar reduction by char.

\section{EXPERIMENTAL}

\section{A. Coal Sample}

Indonesian sub-bituminous coal (Adaro coal, AD) of 0.5 to $1.0 \mathrm{~mm}$ was used. The coal properties are shown in Table I. These samples were dried under vacuum for $8 \mathrm{~h}$ prior to use.

TABLE I: ULTIMATE ANALYSIS OF ADARO COAL

\begin{tabular}{lcccccc}
\hline \hline & $\mathrm{C}$ & $\mathrm{H}$ & $\mathrm{N}$ & $\mathrm{S}$ & $\mathrm{O}($ diff $)$ & Ash \\
\cline { 2 - 7 } & \multicolumn{6}{c}{$(\mathrm{wt} \%$, dry ash free) } \\
\hline $\mathrm{AD}$ & 70.4 & 4.8 & 0.9 & 0.1 & 24.0 & 0.6 \\
\hline
\end{tabular}

\section{B. Experimental Procedure}

We developed a novel type of circulating fluidized bed reactor consisting of a bubbling bed pyrolyzer and combustor. All reactors were made of quartz. A schematic diagram of the experimental apparatus is shown in Fig. 1. Silica sand (JIS 
\#8) that is inert for tar reforming was used as a bed material. Gold image electric furnaces were used for heating the reactors and we could therefore observe the fluidizing state of solids and the reaction behavior of samples at high temperature.

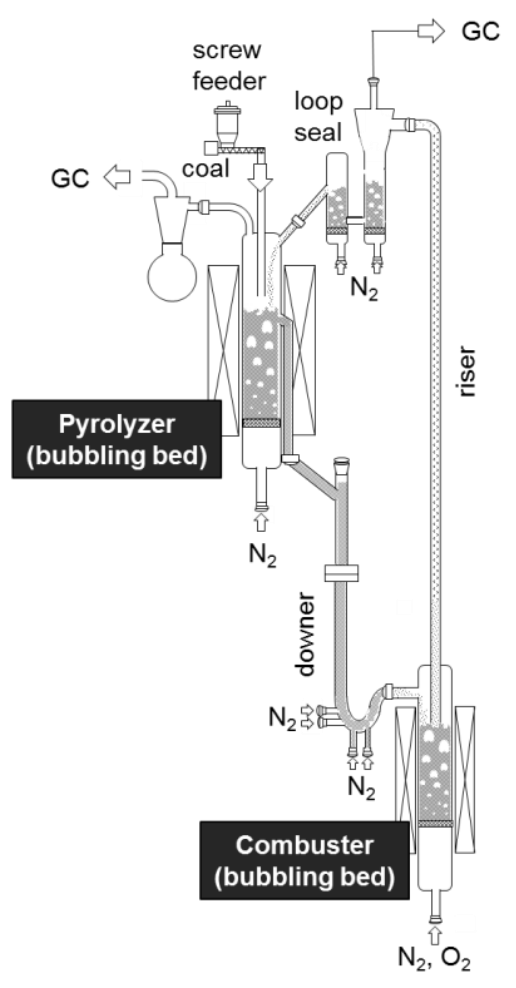

Fig. 1. Schematic diagram of CFB.

The pyrolyzer and combustor were heated to $700-900^{\circ} \mathrm{C}$ and $850^{\circ} \mathrm{C}$, respectively, while maintaining bed material circulation. The circulating rate $\left(\mathrm{G}_{\mathrm{s}}\right)$ was maintained at $\sim 1.2$ $\mathrm{kg} \mathrm{m}^{-2} \mathrm{~s}^{-1}$. After stabilization of the solids circulation, we started feeding raw coal to the pyrolyzer using a screw feeder at $0.4 \mathrm{~g} / \mathrm{min}$. The coal was pyrolyzed rapidly, and the volatiles (gases and tar) and char were formed. The resultant char was circulated to the combustor with the bed material to be combusted. Under complete combustion of the char, all chars were converted to $\mathrm{CO}_{2}$, and then, only the bed material was circulated back to the pyrolyzer. Under partial combustion conditions, a portion of the char was combusted and some of the char remained and was recycled to the pyrolyzer with the bed material (this condition is defined as the char recycling mode). The concentration of recycled char in the pyrolyzer increased as a result of the continuous char recycling. The char recycling was continued for $4 \mathrm{~h}$. During char recycling, the recycled char can be contacted with volatiles produced from the pyrolysis of raw coal from the feeder, thereby enhancing the volatile-char interaction (VCI).

Gas chromatography (GC) was used to analyze the gases derived from each reactor. Heavy and light tar (smaller molecular weight such as benzene, toluene, and naphthalene) was sampled from two different ports as shown in Fig. 1. Heavy tar was collected using a glass wool thimble filter. The filter was washed with tetrahydrofuran and the solution was then allowed to evaporate. The residue was subjected to an ultimate analysis. Light tar was extracted using a syringe and was washed with methanol. The methanol solution was analyzed by GC-mass spectrometry.

\section{RESULTS AND DISCUSSION}

\section{A. Product Distribution}

Fig. 2 shows the product distribution (carbon yield) of AD at each pyrolyzer temperature. The total product yield at each pyrolyzer temperature is approximately $100 \mathrm{~mol} / 100 \mathrm{~mol}$ carbon $(\mathrm{C})$, which indicates that a good mass balance was achieved.

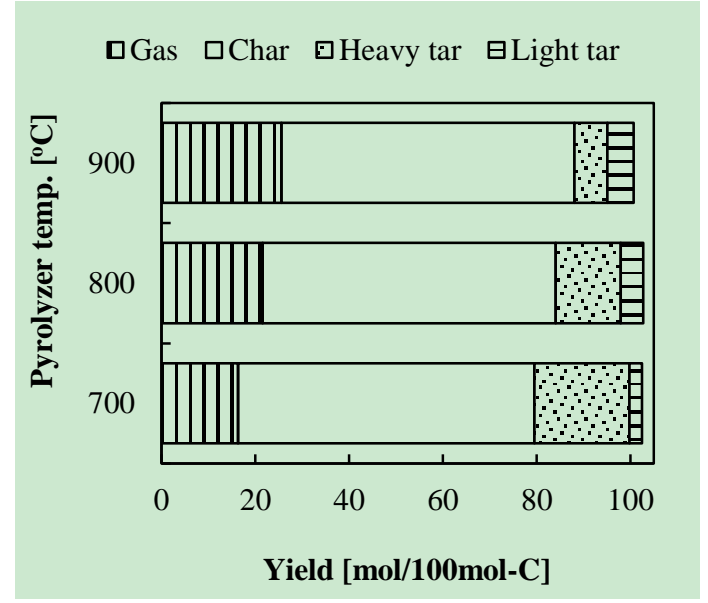

Fig. 2. Product distribution of $\mathrm{AD}$ at each pyrolyzer temperature.

\section{B. Increasing Gas Yield with Char Recycling}

Fig. 3 shows that the product gas yield increased with char recycling over $4 \mathrm{~h}$ during pyrolysis. $\mathrm{H}_{2}$ and $\mathrm{CO}$ yields are plotted in Fig. 3 (a) and (b), respectively. These yields increased with increasing pyrolyzer temperature without char recycling. The $\mathrm{H}_{2}$ and $\mathrm{CO}$ yields were also enhanced by char recycling, which suggests that the tar was deposited on the recycled char as a coke and was reformed by steam derived from pyrolysis. Though not shown here, the yields of other gases such as $\mathrm{CO}_{2}, \mathrm{CH}_{4}$, and $\mathrm{C}_{2}$ were independent of char recycling.

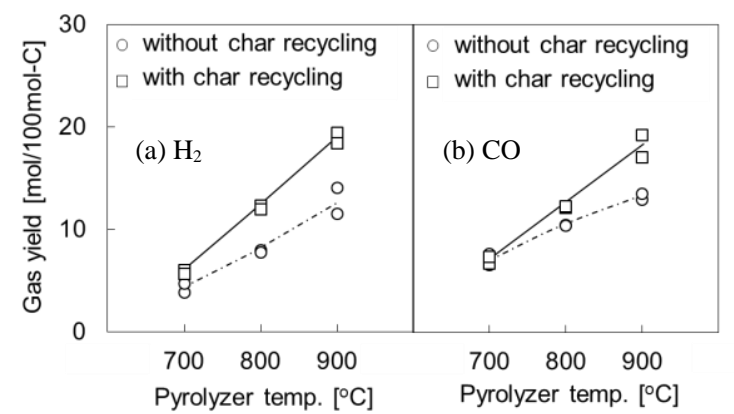

Fig. 3. Product gas yield during pyrolysis at each pyrolyzer temperature with or without char recycling for $4 \mathrm{~h}$. (a) $\mathrm{H}_{2}$ yield, (b) $\mathrm{CO}$ yield.

\section{Reduction of Light Tar with Char Recycling}

The variation in light tar abundance (benzene, toluene, xylene, phenol, naphthalene, and phenanthrene) during pyrolysis with char recycling time is shown in Fig. 4. The yield of each material formed without char recycling is shown for zero char recycling time. Fig. 4 (a) to (b) show the yield at pyrolyzer temperatures of $700^{\circ} \mathrm{C}, 900^{\circ} \mathrm{C}$, respectively.

The results for each pyrolyzer temperature indicate a 
decrease in light tar yield with char recycling. The VCI was therefore enhanced during char recycling, and some of the light tars were deposited on the char and then reformed.

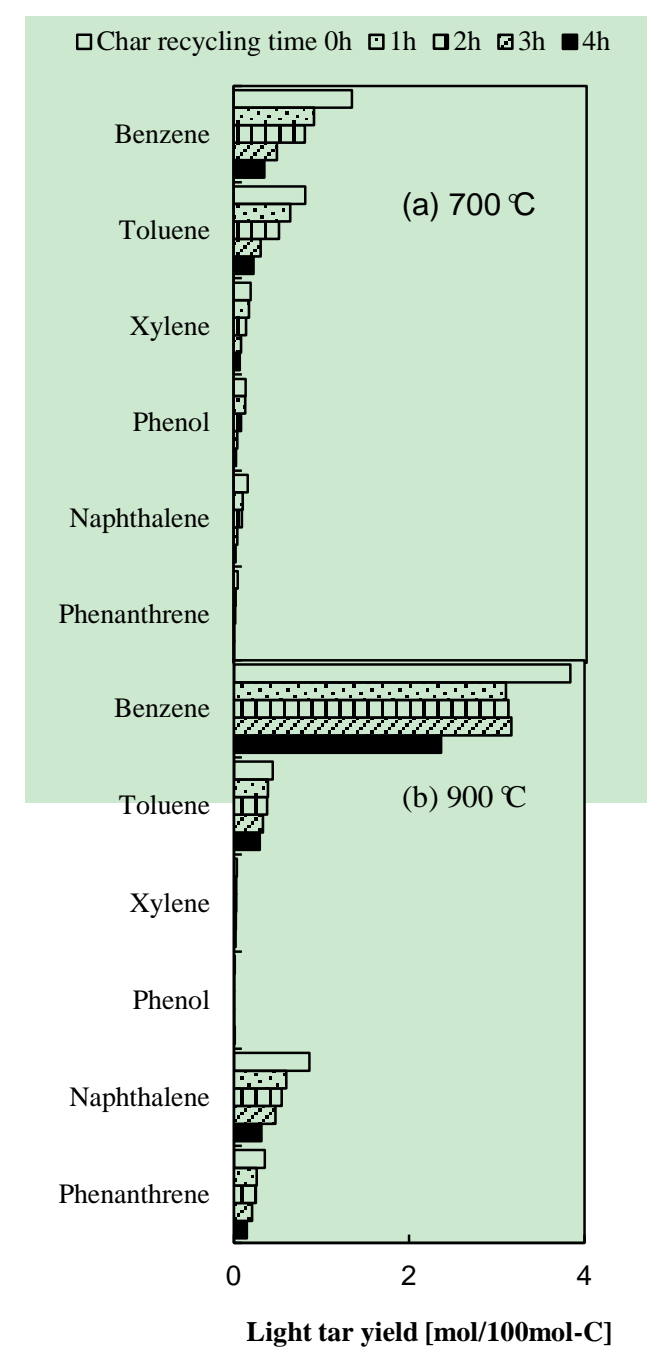

Fig. 4. Variation of light tar yield for $\mathrm{AD}$ with char recycling time at pyrolyzer temperatures of (a) $700^{\circ} \mathrm{C}$, (b) $900^{\circ} \mathrm{C}$.

\section{Decrease of Heavy tar Yield with Char Recycling}

Fig. 5 shows the variation of heavy tar yield for the AD with char recycling during pyrolysis at each pyrolyzer temperature. The yield at $0 \mathrm{~h}$ equates to that without char recycling. The heavy tar yield was lower with increasing pyrolyzer temperature. Secondary gas phase decomposition of tar derived from pyrolysis therefore occurred [23]. The heavy tar yield at each pyrolyzer temperature decreased with char recycling time. At $700^{\circ} \mathrm{C}$ and $800^{\circ} \mathrm{C}$, the heavy tar yield decreased significantly. At $900^{\circ} \mathrm{C}$, the decrease of tar yield leveled off at a char recycling time of $1.2 \mathrm{~h}$. Li-xin et al. [18] examined the cracking/reforming of tar in a DTF reactor and found that more than $70 \%$ of the tar could be reduced by co-feeding the char with raw Australian Loy Yang lignite at a mixing ratio of 5.7 (char/coal) and $900^{\circ} \mathrm{C}$. Although the mixing ratio of $\mathrm{AD}$ char with raw coal was approximately 20 after $4 \mathrm{~h}$ char recycling under our experimental conditions, the tar reduction was much lower than that reported by $\mathrm{Li}$-xin et al. We confirm that the raw coal was pyrolyzed to evacuate volatile matter after fluidization in the dense bed from direct observation. This indicates that char can be contacted with pyrolysis-driven volatiles, but the contact was insufficient to reduce the tar. The effect of char contact with volatiles on tar reduction will be examined in future.

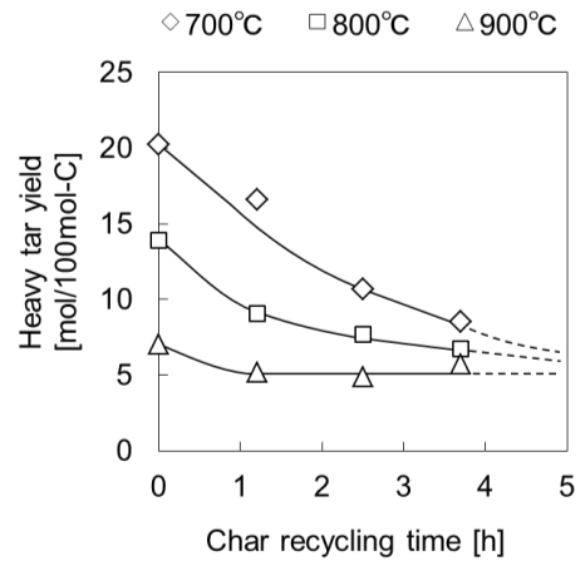

Fig. 5. Variation of heavy tar yield of AD with char recycling at each pyrolyzer temperature.

\section{E. Pore Structure of Recycled Chars}

The above results suggest that light and heavy tar was deposited on the char and that the char structure changed. Fig. 6 shows the Brunauer-Emmett-Teller (BET) specific surface area $\left(a_{\mathrm{s}}\right)$ of recycled chars at different pyrolyzer temperatures.

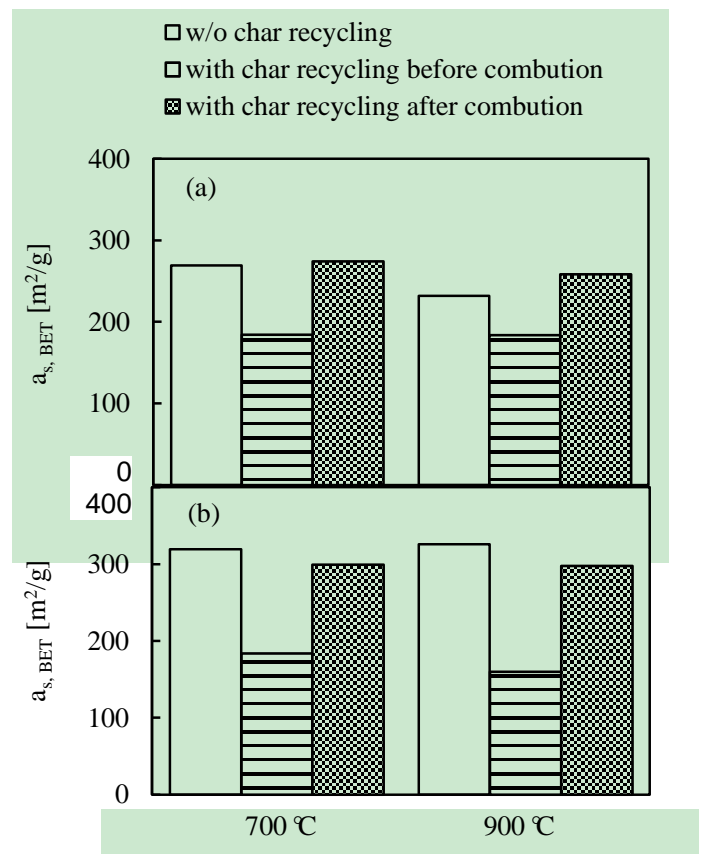

Fig. 6. Variation of BET specific surface area of AD chars discharged from CFB before and after char recycling. (a): 500-1000 $\mu \mathrm{m}$ and (b): 250-500 $\mu \mathrm{m}$ in diameter.

In Fig. 6, "without char recycling" refers to the specific surface area of the chars sampled at the bottom of the downer (cf. Fig. 1). The terms "with char recycling before combustion" and "with char recycling after combustion" refer to the specific surface area of the chars sampled at the bottom of the downer after char recycling for $4 \mathrm{~h}$ and that after partial combustion, respectively. These results indicate that tar was deposited in the pores of the char and that some of the coke was combusted to regenerate the coke deposited in the pores. 


\section{CONCLUSION}

We examined the possibility of the reduction or reforming of tar with enhancing VCI (by char recycling) in a circulating fluidized bed reactor. The light and heavy tar content could be decreased without using a catalyst, and the product gas could be increased. The light and heavy tar deposited on the char surface and the deposited tar would be reformed by the steam derived from pyrolysis.

\section{REFERENCES}

[1] Y. Ishibashi, "The completion of the air-blown IGCC demonstration test and its conversion to commercial use,"World Energy Council, Oct. 2013.

[2] G. Guan, C. Fushimi, A. Tsutsumi, M. Ishizuka, S. Matsuda, H. Matsuda, H. Hatano, and Y. Suzuki, "High-density circulating fluidized bed gasifier for advanced IGCC/IGFC-Advantages and challenges," Particuology, vol. 8, pp. 602-606, 2010.

[3] K. Matsuoka, S. Hosokai, K. Kuramoto, and Y. Suzuki, "Enhancement of coal char gasification using a pyrolyzer-gasifier isolated circulating fluidized bed gasification system," Fuel Processing Technology, vol. 109, pp. 43-48, 2013.

[4] M. P. Houben, H. C. de Lange, and A. A. van Steenhoven, "Tar reduction through partial combustion of fuel gas," Fuel, vol. 84, pp $817-824,2005$

[5] T. A. van der Hoeven, H. C. de Lange, and A. A. van Steenhoven, "Analysis of hydrogen-influence on tar removal by partial oxidation," Fuel, vol. 85, pp.1101-1110, 2006

[6] C. Myrén, C. Hörnell, E. Björnbom, and K. Sjöström, “Catalytic tar decomposition of biomass pyrolysis gas with a combination of dolomite and silica," Biomass and Bioenergy, vol. 23, pp. 217-227, 2002.

[7] A. Sarığlan, "Tar removal on dolomite and steam reforming catalyst: Benzene, Toluene and Xylene reforming," International Journal of Hydrogen Energy, vol. 37, pp. 8133-8142, 2012.

[8] R. B. Cahyono, A. N. Rozhan, N. Yasuda, T. Nomura, S. Hosokai, Y. Kashiwaya, and T. Akiyama, "Catalytic coal-tar decomposition to enhance reactivity of low-grade iron ore," Fuel Processing Technology, vol. 113, pp. 84-89, 2013.

[9] F. M. Josuinkas, C. P. B. Quitete, N. F. P. Ribeiro, and M. M. V. M. Souza, "Steam reforming of model gasification tar compounds over nickel catalysts prepared from hydrotalcite precursors," Fuel Processing Technology, vol. 121, pp. 76-82, 2014.

[10] R. Li, A. Roy, and K. M. Dooley, "Tar Reforming in model gasifier effluents: transition metal/rare earth oxide catalysts," Industrial \& Engineering Chemistry Research, vol. 53, pp. 7999-8011, 2014.

[11] J. I. Hayashi, M. Iwatsuki, K. Morishita, A. Tsutsumi, C. Z. Li, and T. Chiba, "Roles of inherent metallic species in secondary reactions of tar and char during rapid pyrolysis of brown coals in a drop-tube reactor,' Fuel, vol. 81, pp. 1977-1987, 2002.

[12] O. Mašek, N. Sonoyama, E. Ohtsubo, S. Hosokai, C. Z. Li, T. Chiba, and J. I. Hayashi, "Examination of catalytic roles of inherent metallic species in steam reforming of nascent volatiles from the rapid pyrolysis of a blown coal," Fuel Processing Technology, vol. 88, pp. 179-185, 2007.

[13] S. Hosokai, K. Kumabe, M. Ohshita, K. Norinaga, C. Z. Li, and J. I. Hayashi, "Mechanism of decomposition of aromatics over charcoal and necessary condition for maintaining its activity," Fuel, vol. 87, pp. 2914-2922, 2008.

[14] S. Zhang, J. I. Hayashi, and C. Z. Li, "Volatilisation and catalytic effects of alkali and alkaline earth metallic species during the pyrolysis and gasification of Victorian blown coal. Part IX. Effects of volatile-char interactions on char- $\mathrm{H}_{2} \mathrm{O}$ and Char- $\mathrm{O}_{2}$ reactivities," Fuel, vol. 90, pp. 1655-1661, 2011.

[15] Z. Min, P. Yimsiri, M. Asadullah, S. Zhang, and C. Z. Li, "Catalytic reforming of tar during gasification. Part II. Char as a catalyst or as a catalyst support for tar reforming," Fuel, vol. 90, pp. 2545-2552, 2011.

[16] S. Kajitani, H. L. Tay, S. Zhang, and C. Z. Li, "Mechanisms and kinetic modelling of steam gasification of brown coal in the presence of volatile-char interactions," Fuel, vol. 103, pp. 7-13, 2013.

[17] C. Z. Li, "Importance of volatile-char interactions during the pyrolysis and gasification of low rank fuels - A review," Fuel, vol. 112, pp. 609-623, 2013.

[18] L. X. Zhang, T. Matsuhara, S. Kudo, J. I. Hayashi, and K. Norinaga, "Rapid pyrolysis of brown coal in a drop-tube reactor with co-feeding of char as a promoter of in situ tar reforming," Fuel, vol. 112, pp. 681-686, 2013.

[19] K. Matsuoka, S. Hosokai, Y. Kato, K. Kuramoto, Y. Suzuki, K. Norinaga, and J. I. Hayashi, "Promoting gas production by controlling the interaction of volatiles with char during coal gasification in a circulating fluidized bed gasification reactor," Fuel Processing Technology, vol. 116, pp. 308-316, 2013.

[20] J. Han, X. Wang, J. Yue, S. Gao, and G. Xu, "Catalytic upgrading of coal pyrolysis tar over char-based catalysts," Fuel Processing Technology, vol. 122, pp. 98-106, 2014.

[21] Y. Song, Y. Wang, X. Hu, J. Xiang, L. Zhang, S. Zhang, Z. Min, and C. Z. Li, "Effects of volatile-char interactions on in situ destruction of nascent tar during the pyrolysis and gasification of biomass. Part I. Roles of nascent char," Fuel, vol. 122, pp. 60-66, 2014.

[22] F. J. Wang, S. Zhang, Z. D. Chen, C. Liu, and Y. G. Wang, "Tar reforming using char as catalyst during pyrolysis and gasification of Shengli brown coal," Journal of Analytical and Applied Pyrolysis, vol. 105, pp. 269-275, 2014.

[23] J. C. Chen, C. Castagnoli, and S. Niksa, "Coal Devolatilization during rapid transient heating. 2. secondary pyrolysis," Energy \& Fuels, vol. 6, pp. 264-271, 1992.

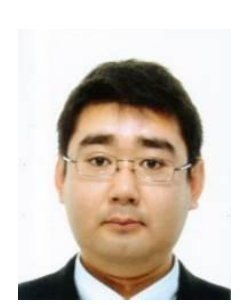

Yasumasa Kawabata was born in Aomori prefecture, Japan, in September, 1989. He received his associate degree in engineering from Hachinohe National College of Technology, Hachinohe, Aomori Prefecture, Japan in 2010, and his bachelor's and master's degrees in engineering from Chiba University, Chiba, Chiba Prefecture, Japan in 2012 and 2014, respectively.

He commenced his doctoral course in the Department of Urban Environment Systems, Graduate School of Engineering, Chiba University, Japan, in 2014. 